\title{
Granular cell tumour: malignant or benign?
}

\author{
Vivek Ajit Singh ${ }^{1}$, MS, FRCSE, Jayaletchumi Gunasagaran ${ }^{1}$, MBBS, Jayalakshmi $\underline{\text { Pailoor }}^{2}$, MRCPath, FRCPath
}

INTRODUCTION Granular cell tumours (GrCTs) are uncommon soft tissue tumours that are usually benign (approximately $0.5 \%-2.0 \%$ have been reported as malignant). They are very rarely found at the extremities. Differentiating a malignant GrCT from a benign one is important as the former is aggressive and has a poor prognosis, whereas the latter, after surgical resection, has excellent outcomes. A malignant lesion can be suspected on clinical presentation and confirmed via histopathological examination using the Fanburg-Smith criteria.

METHODS This was a retrospective review of all cases of GrCT of the extremities that presented to the Orthopaedic Oncology Unit of University Malaya Medical Centre, Malaysia, from September 2006 to March 2013.

RESULTS There were a total of five cases, all of which involved female patients aged 13-40 (mean age 24) years. Three cases involved the upper limbs and two involved the lower limbs. Using the Fanburg-Smith criteria, three cases were classified as benign, one as atypical and one as malignant. Wide local excision was performed in all five cases and the outcomes were excellent except for the patient with a malignant tumour. That patient presented with lung metastasis about three months after surgery.

CONCLUSION Malignant and benign GrCTs can be differentiated on clinical presentation and by using the Fanburg-Smith criteria. We believe that wide local excision is the best treatment for both benign and malignant tumours. The role of adjuvant chemotherapy and radiotherapy in malignant GrCTs should be studied. All patients with GrCTs should receive follow-up to check for recurrence and metastasis.

Keywords: benign, granular cell tumour, malignant

\section{INTRODUCTION}

A granular cell tumour ( $\mathrm{GrCTs})$ is a rare, benign, soft tissue tumour $^{(1)}$ that likely arises from Schwann cells. ${ }^{(2)}$ Although it was initially classified as a myoblastoma, recent studies agree that it is more likely to be neural in origin. ${ }^{(2,3)} \mathrm{GrCTs}$, although typically found in the tongue or the dermal and subcutaneous regions, can appear at any location. ${ }^{(2)} \mathrm{GrCTs}$ are rarely found in the extremities.

Approximately $0.5 \%-2.0 \%$ of $\mathrm{GrCTs}$ are reported as malignant. ${ }^{(1)}$ A malignant GrCT is aggressive and has a poor prognosis, ${ }^{(4)}$ whereas a benign lesion has excellent outcomes after surgical resection. ${ }^{(1)}$ Malignant $\mathrm{GrCTs}$ have a high rate of metastasis and recurrence, with a mortality rate of $40 \%$. $^{(2)}$ Thus, differentiating a malignant tumour from a benign tumour is important. A malignant lesion can be suspected on clinical presentation and confirmed via histopathological examination using the Fanburg-Smith criteria. ${ }^{(4,5)}$

We herein report a case series of five patients who were diagnosed with GrCT of the extremities at University Malaya Medical Centre, Kuala Lumpur, Malaysia. The clinical presentation, and histopathological and immunohistochemical results of these five cases were evaluated.

\section{METHODS}

This study was a retrospective review of all cases of GrCT of the extremities who presented at the Orthopaedic Oncology Unit of University Malaya Medical Centre, Kuala Lumpur, Malaysia, from September 2006-March 2013. The cases were identified from the orthopaedic oncology database and the corresponding medical records were traced. The histopathology slides were also traced and reviewed.

\section{RESULTS}

Five patients were diagnosed with $\mathrm{GrCT}$ of the extremities at the medical centre during the study period. The clinical details of the patients are shown in Table I. All the patients were female and their mean age, at the time of presentation, was 24 (range 13-40) years. All five patients presented with a single swelling, which was located at different sites of the extremities, and no constitutional symptoms. Three cases involved the upper limbs (i.e. the scapular region, arm and forearm) and two cases involved the lower limbs. The largest tumour measured $8 \mathrm{~cm} \times 5 \mathrm{~cm}$ and was located in a lower limb.

The swelling was painless in three of the patients, while one patient had occasional pain when pressure was applied and one had constant pain associated with lymphadenopathy (at the inguinal region on the same side as the tumour). The duration of the symptoms at presentation ranged from six months to six years. In two cases, the tumour was a recurrence. The first of these cases was due to inadequate resection at another centre prior to presentation at our centre; the recurrence occurred within a month after the inadequate resection. The second case involved a 40-year-old patient whose tumour recurred twice despite wide local excisions performed previously at another centre. The patient presented at our centre with complaints of recurrent painful swelling over the anterior aspect of her distal leg (Fig. 1); the pain was associated with ipsilateral inguinal lymphadenopathy. She had undergone wide local excisions twice at a private centre and the 
Table I. Clinical data, presentation and post-surgical outcomes of the patients $(n=5)$.

\begin{tabular}{|c|c|c|c|c|c|c|c|c|}
\hline Patient & $\begin{array}{l}\text { Age } \\
\text { (yr) }\end{array}$ & Gender & Tumour site & $\begin{array}{c}\text { Tumour } \\
\text { size } \\
\text { (cm) }\end{array}$ & $\begin{array}{c}\text { Duration } \\
\text { of tumour } \\
(\mathrm{yr})\end{array}$ & Presentation & $\begin{array}{c}\text { Duration of } \\
\text { follow-up } \\
\text { (yr) }\end{array}$ & $\begin{array}{l}\text { Post-surgical } \\
\text { outcome }\end{array}$ \\
\hline 1 & 19 & Female & Posterior arm & $6 \times 7$ & 1.5 & Painless swelling & 2.50 & Disease-free \\
\hline 2 & 28 & Female & Posterior mid-thigh & $5 \times 5$ & 5.0 & Recurrent painless swelling & 0.25 & Disease-free \\
\hline 3 & 13 & Female & $\begin{array}{l}\text { Lateral proximal } \\
\text { forearm }\end{array}$ & $2 \times 2$ & 6.0 & Painless swelling & 1.00 & Disease-free \\
\hline 4 & 40 & Female & $\begin{array}{l}\text { Anterior distal } \\
\text { thigh }\end{array}$ & $8 \times 5$ & 0.5 & $\begin{array}{l}\text { Recurrent painful swelling } \\
\text { with lymphadenopathy }\end{array}$ & 1.50 & $\begin{array}{l}\text { Metastasis } \\
\text { to lung }\end{array}$ \\
\hline 5 & 20 & Female & Scapular region & $3 \times 3$ & 1.5 & Swelling with occasional pain & 0.50 & Disease-free \\
\hline
\end{tabular}

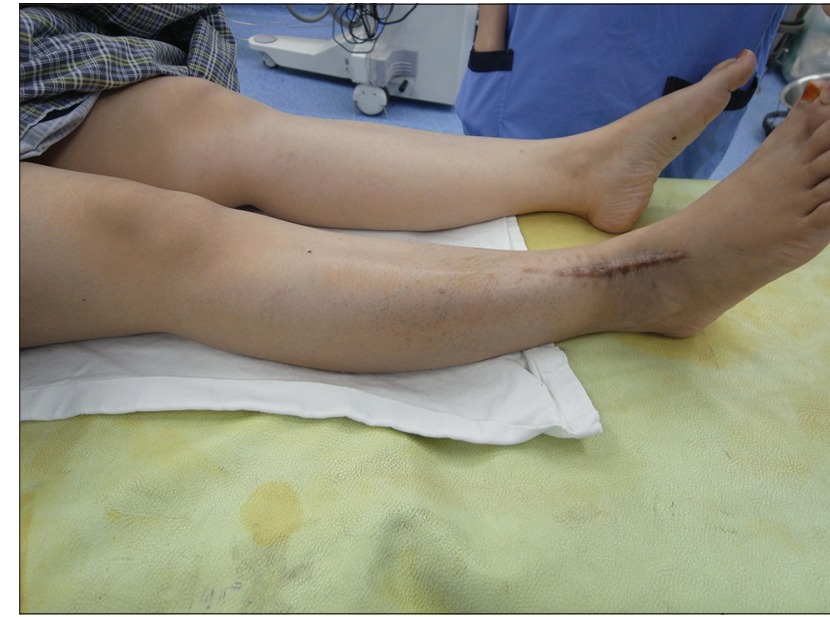

Fig. 1 Patient 2: Photograph shows swelling over the right calf, above the site of the previous resection (marked by the scar). Some dilated veins are visible over the swelling.

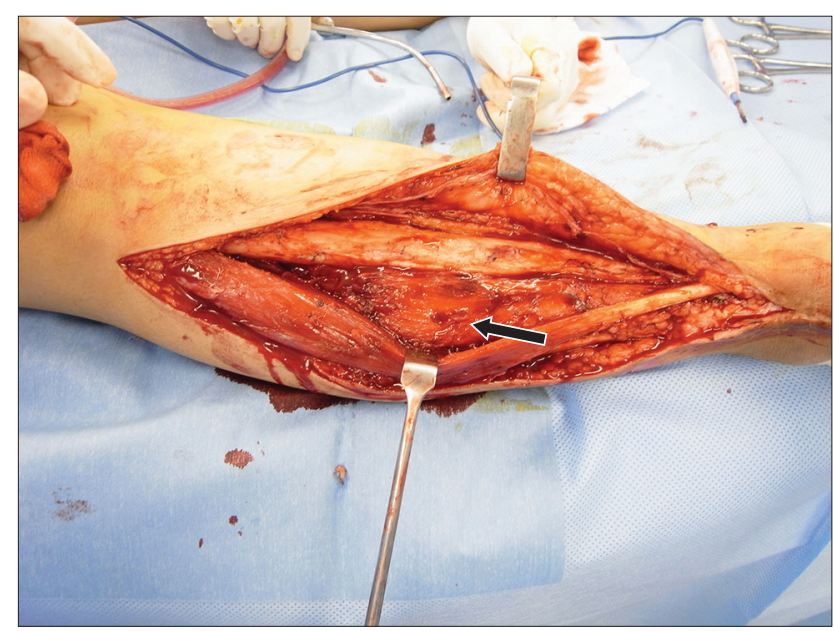

Fig. 3 Patient 2: Photograph shows the intraoperative view of the tumour (arrow), which is attached to the lateral border of the tibia.

histological results of both resections indicated that the tumour was a GrCT. Her tumour was the largest $(8 \mathrm{~cm} \times 5 \mathrm{~cm})$ among all five cases (Fig. 2). Resection of the tumour and reconstruction was performed at our centre (Fig. 3). The tumour was hard, fixed to the underlying tissues and had been rapidly increasing in size during the six months prior to her presentation. We planned adjuvant chemotherapy and radiotherapy for the patient after wide local excision of the tumour. However, she opted for palliative treatment, as she was not keen on chemotherapy.
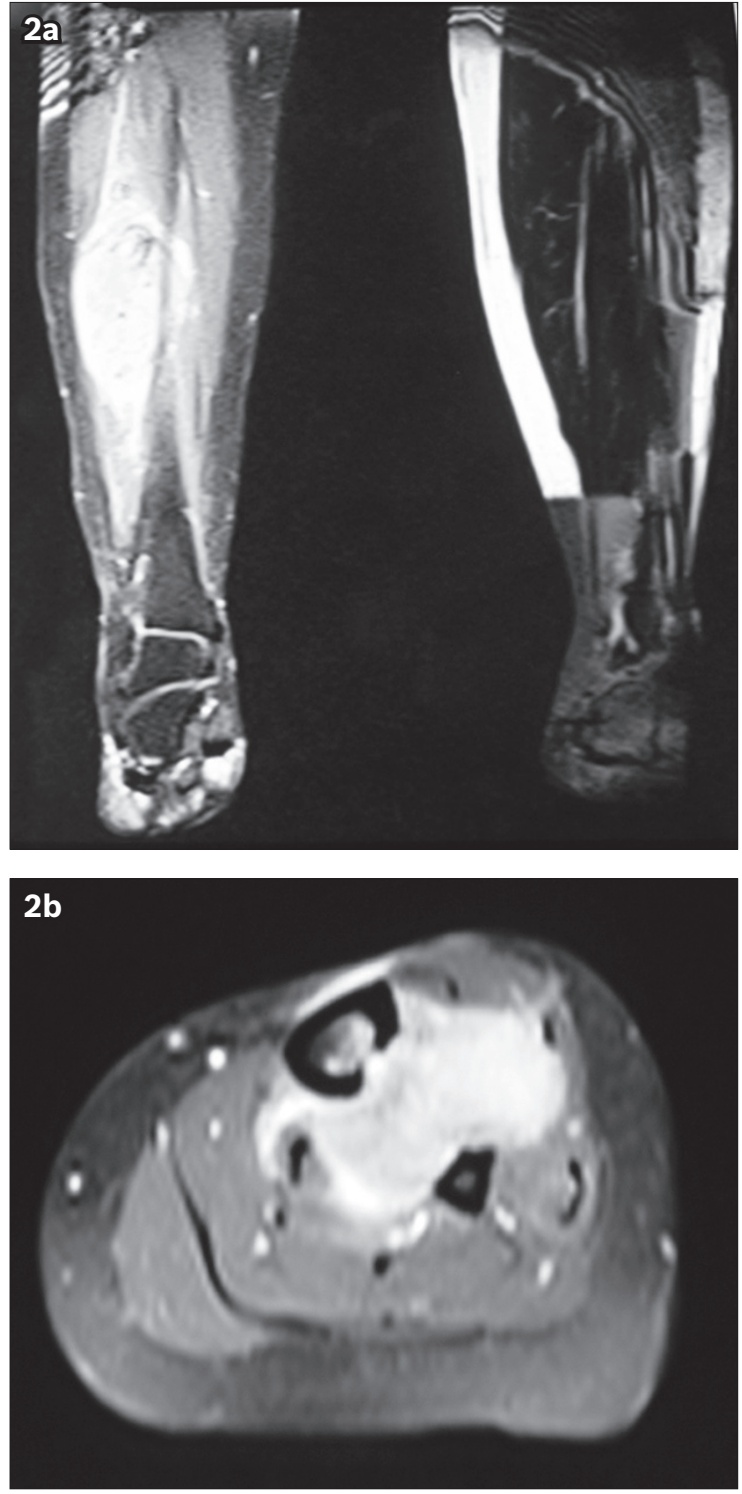

Fig. 2 Patient 2: T2-W MR images show the (a) sagittal and (b) axial view of the recurrent tumour in the midsection of the calf. The tumour extends to the lateral border of the tibia and into the interosseous space between the tibia and fibula.

Wide local excision was performed in all five cases, after which the five patients were followed up at our clinic. The average follow-up duration was 14 months. One of the patients defaulted follow-up after three months. All patients were diseasefree at their last follow-up, except for the aforementioned patient 
Table II. Fanburg-Smith criteria and immunohistochemical findings.

\begin{tabular}{lllllllll}
\hline Patient & \multicolumn{9}{c}{ Fanburg-Smith criteria } & Diagnosis & $\begin{array}{l}\text { Immunohistochemical } \\
\text { staining (+ve) }\end{array}$ \\
\cline { 2 - 6 } & $\begin{array}{l}\text { Spindling } \\
\text { cells }\end{array}$ & $\begin{array}{l}\text { Increased } \\
\text { nuclear: } \\
\text { cytoplasmic } \\
\text { ratio }\end{array}$ & $\begin{array}{l}\text { Vesicular } \\
\text { nuclei, } \\
\text { large } \\
\text { nucleoli }\end{array}$ & $\begin{array}{l}\text { Pleomorphic } \\
\text { nuclei }\end{array}$ & Necrosis & $\begin{array}{l}\text { Increased } \\
\text { mitotic } \\
\text { activity }\end{array}$ & & \\
\hline 1 & NA & NA & NA & NA & NA & NA & Benign & NA \\
2 & NA & X & NA & $x$ & $x$ & $x$ & Benign & S100, NSE, Vimentin \\
3 & NA & NA & NA & NA & NA & NA & Benign & CD68, S100, NSE, Vimentin \\
4 & $\checkmark$ & $x$ & $\checkmark$ & $\checkmark$ & $x$ & $\checkmark$ & Malignant & S100 \\
5 & NA & NA & NA & $\checkmark$ & $x$ & NA & Atypical & CD68, S100, NSE \\
\hline
\end{tabular}

NA: not available; NSE: neuron-specific enolase
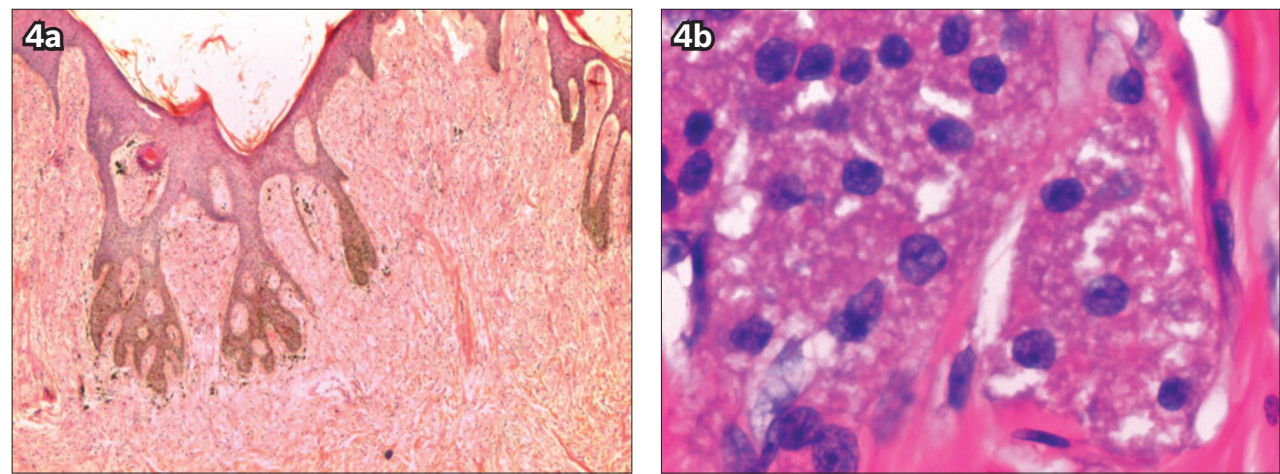

Fig. 4 Patient 2: Photomicrographs show (a) an unencapsulated and infiltrating tumour (Haematoxylin \& eosin, $\times 20$ ); and (b) cords of cells, hyperchromatic nuclei and granular cytoplasm, indicating a benign tumour (Haematoxylin \& eosin, $\times 400$ ).
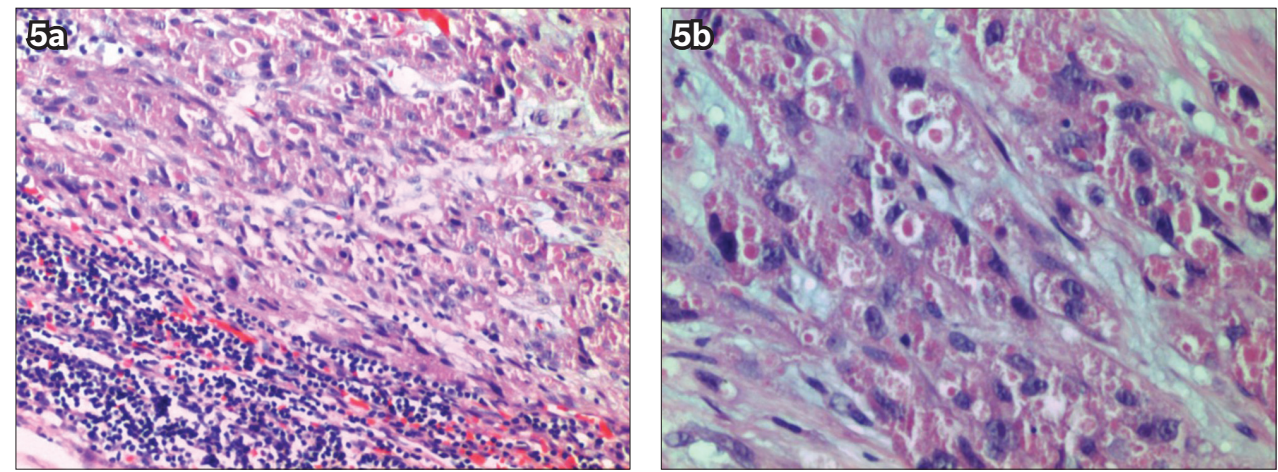

Fig. 5 Patient 4: Photomicrographs show (a) malignant cells with remnant lymphoid tissue (Haematoxylin \& eosin, $\times 100)$; and (b) sheets and nests of round to polygonal cells with eosinophilic granular cytoplasm, and pleomorphic nuclei with prominent nucleoli (Haematoxylin \& eosin, $\times 200$ ).

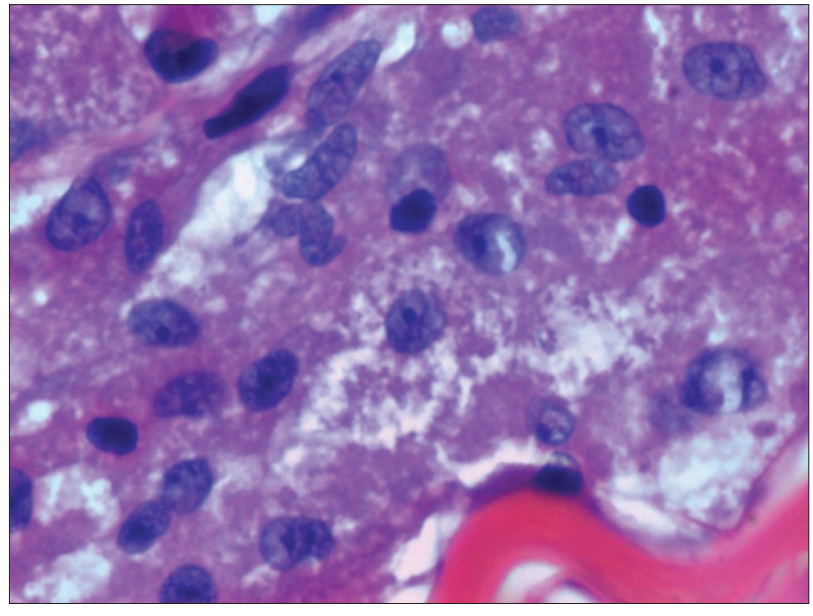

Fig. 6 Patient 5: Photomicrograph shows tumour cells with pleomorphic nuclei and eosinophilic, coarse granular cytoplasm, indicating an atypical tumour (Haematoxylin \& eosin, × 400). with the largest tumour. She was found to have lung metastasis during a routine follow-up surveillance about three months after the surgery. At the time of writing, the patient was alive and with the disease.

The histopathological reports on the resected specimens from all five cases were evaluated. A consultant pathologist's advice was obtained on the characteristic features of GrCT and the features that were indicative of malignancy, based on the Fanburg-Smith criteria. ${ }^{(6)}$ The six histological features of the Fanburg-Smith criteria are listed in Table II; tumours exhibiting three or more features were diagnosed as malignant, tumours exhibiting 1-2 features were diagnosed as atypical, and tumours exhibiting none of the features were diagnosed as benign. In the present study, three of the cases were classified as benign (Fig. 4), one was classified as malignant (Fig. 5) and one was classified as atypical (Fig. 6) 
Table III. Summary of case series on granular cell tumours (GrCTs) at the extremities.

\begin{tabular}{|c|c|c|c|c|c|c|}
\hline Study & Year & $\begin{array}{l}\text { No. of GrCTs at } \\
\text { the extremities }\end{array}$ & $\begin{array}{l}\text { Site of } \\
\text { tumour }\end{array}$ & $\begin{array}{c}\text { No. of } \\
\text { malignant GrCTs }\end{array}$ & Outcome & $\begin{array}{l}\text { Average follow-up } \\
\text { duration (yr) }\end{array}$ \\
\hline Elkousy et $\mathrm{al}^{(1)}$ & 2000 & 10 & $\begin{array}{l}6 \mathrm{LL} \\
4 \mathrm{UL}\end{array}$ & 0 & Disease-free & 2.25 \\
\hline Blacksin et $\mathrm{al}^{(7)}$ & 2005 & 5 & $\begin{array}{l}3 \mathrm{LL}, \\
2 \mathrm{UL}\end{array}$ & 1 & Disease-free & 3.00 \\
\hline Thacker et $\mathrm{al}^{(4)}$ & 2006 & 3 & $\begin{array}{l}2 \mathrm{LL} \\
1 \mathrm{UL}\end{array}$ & 2 & $\begin{array}{l}1 \text { died of disease, } \\
2 \text { disease-free }\end{array}$ & 1.00 \\
\hline Torrijos-Aguilar et al (2) & 2009 & 5 & $\begin{array}{l}4 \mathrm{LL}, \\
1 \mathrm{UL}\end{array}$ & 0 & Disease-free & $4.00-27.00$ \\
\hline Arai et $\mathrm{al}^{(5)}$ & 2010 & 5 & $5 \mathrm{LL}$ & 1 & 1 died of disease, 4 disease-free & 3.75 \\
\hline Rekhi et $\mathrm{al}^{(3)}$ & 2010 & 6 & $\begin{array}{l}3 \mathrm{LL}, \\
3 \mathrm{UL}\end{array}$ & 2 & $\begin{array}{l}1 \text { metastasis to lymph nodes, } \\
5 \text { unknown }\end{array}$ & - \\
\hline Present study & 2015 & 5 & $\begin{array}{l}3 \mathrm{LL} \\
2 \mathrm{UL}\end{array}$ & 1 & 1 metastasis to lung & 1.15 \\
\hline
\end{tabular}

LL: lower limb; UL: upper limb

\section{DISCUSSION}

Although GrCTs were initially classified as myoblastomas, recent studies show that they are of neural origin. (3,6) $\mathrm{GCTS}$ rarely occur at the extremities. From our literature search, we found a total of 56 publications on GrCTs of the upper and lower extremities. The majority of these publications were case reports and only six were case series reports on three or more patients (Table III).

GrCTs are commonly found in female patients aged 20-40 years. ${ }^{(6)}$ The usual presentation is an asymptomatic, slowgrowing solitary mass. ${ }^{(2)}$ In the present study, all five patients had similar presentations except for the patient who was diagnosed with a malignant tumour. Malignant GrCTs have a high propensity for metastasis and recurrence, with a mortality rate of $40 \%$. $^{(3)}$ The malignant variant can be suspected from its clinical presentation. In the present study, the following factors in the patient were highly indicative of the tumour's malignancy: a tumour that was (a) large (> $5 \mathrm{~cm})$, (b) deep-seated at the lower extremities and that (c) showed rapid recent growth, local recurrence and distant metastasis; and being of (d) an older age group and (e) of female gender. ${ }^{(3,7)}$ The common sites for metastasis are the lungs, lymph nodes and bones. ${ }^{(6)}$ A few studies have reported malignant GrCTs in the extremities, commonly involving the thighs. ${ }^{(5,6)}$

A diagnosis of GrCT can be made easily as such tumours have distinctive histological features. ${ }^{(2,3)}$ However, the origin of the cells and its pathogenesis are still under debate. GrCTs were initially named 'granular cell myoblastomas' as it was thought that the tumours arose from striated muscle cells. ${ }^{(6)}$ Under microscopy, the tumour cells are visualised as large and polygonal or round in shape, with vesicular nuclei and abundant eosinophilic granular cytoplasm. ${ }^{(2)}$ The cells are usually separated by fine bands of connective tissue ${ }^{(4)}$ or sclerotic collagenous tissue. ${ }^{(6)}$ It is possible for the overlying skin to undergo pseudoepitheliomatous hyperplasia. ${ }^{(4)}$ Currently, the hypothesis that the tumours are neural in origin is widely accepted. Most GrCTs are cytoplasmic and nuclear positive for S-100 and neuron-specific enolase, ${ }^{(6)}$ supporting this hypothesis. GrCTs are also strongly positive for vimentin and CD68. ${ }^{(3,6)}$ The tumours are occasionally found near nerves. $^{(4)}$
The Fanburg-Smith criteria is a useful tool for diagnosing malignant GrCTs. Its six features for malignancy are shown in Table II. In the present study, one patient was diagnosed with a malignant GrCT. The patient's tumour specimen was indicative of spindling cells, vesicular nuclei with large nucleoli, pleomorphic nuclei and increased mitotic activity (> 2 mitoses per $10 \mathrm{hpf}$ ). However, one should note that these histological features are subjective and may be pathologist-dependent. ${ }^{(5)}$

It is challenging to differentiate benign GrCTs from malignant GrCTs histologically. Often, the tumour is not well-circumscribed and can present with a thin capsule or without a capsule. Microscopically, it is frequently poorly encapsulated and grossly infiltrating. ${ }^{(3,5)}$ It is usually found invading the surrounding structures. A case series by Thacker et al included a case in which a tumour was treated as a benign $\mathrm{GrCT}$, according to histological findings, but the patient presented a year later with lung metastasis. ${ }^{(4)}$ Thus, the diagnosis of a malignant GrCT requires evaluation of both clinical findings and histological results.

While the reported extent of surgical excision for GrCTs is variable, wide local excision is recommended, irrespective of the benign or malignant nature of the tumour, so as to ensure negative margins. For benign and atypical tumours, wide local excision is curative. ${ }^{(1)}$ Benign lesions rarely recur unless the resection was incomplete. ${ }^{(4)}$ Tumours that have a high risk of malignancy can be treated using adjuvant radiotherapy, which usually results in a good outcome. ${ }^{(5)}$ Thacker et al reported a case of a malignant GrCT in which the patient received adjuvant radiotherapy after surgery and was disease-free for 17 months. ${ }^{(4)}$ In contrast, Arai et al reported a case of mortality due to lung metastasis despite adjuvant radiotherapy and chemotherapy after surgical resection ${ }^{(5)}$; the patient presented with lymph node metastasis. ${ }^{(5)}$ Khansur et al reported a series of 40 cases of GrCTs -37 were benign and three were malignant tumours ${ }^{(8)}$; the rate of malignant GrCTs was reported to be $7.5 \%$, which is considered high compared to other malignancies. ${ }^{(8)}$ In the present study, there was a case of frank malignancy among the five cases of GrCTs (i.e. a rate of 20\%). As there are no proper guidelines on the management of these tumours, we are of the opinion that it 
is best to carry out wide local resection rather than a marginal resection or observation.

In conclusion, although benign GrCTs have excellent outcomes after wide local excision, malignant GrCTs have poor clinical outcomes and prognoses. Malignant GrCTs can be differentiated from benign GrCTs via thorough examination of the patient during clinical presentation and histological examination of the excised specimen using the Fanburg-Smith criteria. We believe that wide local excision is the best treatment, irrespective of whether the lesion is benign or malignant. The role of adjuvant chemotherapy and radiotherapy is uncertain, but should be considered in patients with recurrent malignant GrCTs or metastatic disease. All patients should be followed up for recurrence and distant metastasis regardless of the initial nature of the disease.

\section{REFERENCES}

1. Elkousy H, Harrelson J, Dodd L, Martinez S, Scully S. Granular cell tumors of the extremities. Clin Orthop Relat Res 2000; (380):191-8.
2. Torrijos-Aguilar A, Alegre-de Miguel V, Pitarch-Bort G, Mercader-García P, Fortea-Baixauli JM. [Cutaneous granular cell tumor: a clinical and pathologic analysis of 34 cases]. Actas Dermosifiliogr 2009; 100:126-32. Spanish.

3. Rekhi B, Jambhekar NA. Morphologic spectrum, immunohistochemical analysis, and clinical features of a series of granular cell tumors of soft tissues: a study from a tertiary referral center. Ann Diagn Pathol 2010; 14:162-7.

4. Thacker MM, Humble SD, Mounasamy V, Temple HT, Scully SP. Case report. Granular cell tumors of extremities: comparison of benign and malignant variants. Clin Orthop Relat Res 2006; 455: 267-73.

5. Arai E, Nishida Y, Tsukushi S, Sugiura H, Ishiguro N. Intramuscular granular cell tumor in the lower extremities. Clin Orthop Relat Res 2010; 468:1384-9

6. Fanburg-Smith JC, Meis-Kindblom JM, Fante R, Kindblom LG. Malignant granular cell tumor of soft tissue: diagnostic criteria and clinicopathologic correlation. Am J Surg Pathol 1998; 22:779-94.

7. Blacksin MF, White LM, Hameed M, et al. Granular cell tumor of the extremity: magnetic resonance imaging characteristics with pathologic correlation. Skeletal Radiol 2005; 34:625-31.

8. Khansur T, Balducci L, Tavassoli M. Granular cell tumor. Clinical spectrum of the benign and malignant entity. Cancer 1987; 60: 220-2. 